Original Research

\title{
Monitoring the transition of patients on biologics in rheumatoid arthritis: Consensus guidance for pharmacists
}

\author{
Denis CHOQUETTE (D), Jonathan CHAN (D), Mohammad BARDI (iD), Carolyn WHISKIN, Gabriel TORANI (iD), \\ Brennan K. SMITH (D), Aaron SIHOTA ID). \\ Received (first version): 29-Mar-2021 Accepted: 4-Jul-2021 Published online: 14-Sep-2021
}

\begin{abstract}
Background: Recent approvals for novel agents such as the small molecule Janus kinase inhibitors (JAKi), combined with the advent of biosimilars has widened the gamut of available therapeutic options in the treatment of rheumatoid arthritis (RA). This combined with the introduction of mandatory non- medical switches to biosimilars in some jurisdictions by both public and private payors has led to a significant increase in the volume of therapeutic changes for patients. Pharmacists are well positioned to ensure effective and safe transitions, however there is a significant unmet need for objective and subjective clinical guidance around therapy as well disease state monitoring in RA that facilitates best practices throughout the patient journey.

Objective: In this paper we aim to create a consensus derived monitoring algorithm for pharmacists to facilitate best practices throughout therapeutic transitions from originator biologic to other originator biologics, biosimilars, and Janus kinase inhibitors in RA. Methods: The Nominal Group Technique (NGT) was used to understand if consensus could be found among the participants. Clinically relevant questions were developed to capture solutions to the identified unmet need. The faculty considered the questions as individuals, and privately generated answers/ideas. After discussion and consideration, the participants ranked the ideas and established a consensus.

Results: Based on the outcome of the consensus discussions, an algorithm was created to help guide pharmacists through therapeutic transitions in RA. The tool covers important topics such as pre-transition considerations, avoiding the nocebo effect for biosimilars, specific considerations for each drug or class, monitoring efficacy, and when to refer.

Conclusions: New classes of anti-rheumatic drugs including JAKi, along with the introduction of biosimilars are presenting more opportunity for therapeutic changes and monitoring in patients with RA. We hope our evidence-based consensus derived guidance
\end{abstract} tool will assist frontline pharmacists in supporting their patients to a successful therapeutic transition in RA.

Keywords

Consensus; Algorithms; Biosimilar Pharmaceuticals; Janus Kinase Inhibitors; Drug Substitution; Antirheumatic Agents; Arthritis, Rheumatoid; Nocebo Effect; Pharmacists; Rheumatologists; Clinical Competence; Group Processes; Canada

\section{INTRODUCTION}

Biologic drugs for the treatment of rheumatoid arthritis (RA) and other inflammatory conditions have been widely used for over 20 years. ${ }^{1}$ The first tumor necrosis factor alpha (TNF- $\alpha$ ) inhibitor, infliximab, was approved by the FDA in 1998. Since then, many other biologics including those with novel mechanisms of action have entered the RA market. In addition, the recent approvals of the small molecule of the Janus kinase inhibitors class (JAKi) provide patients with targeted oral therapeutic options.

There are many reasons why a rheumatologist and their

Denis CHOQUETTE. MD. Rheumatology Institute of Montreal. Montreal, QC (Canada). denis.choquette.irm@videotron.ca Jonathan CHAN. MD. Division of Rheumatology, Department of Medicine, University of British Columbia. Vancouver, BC (Canada). vanrheumclinic@gmail.com

Mohammad BARDI. MD. Division of Rheumatology, Department of Medicine, University of British Columbia. Vancouver, BC (Canada). mobardi@gmail.com

Carolyn WHISKIN. BScPharm, RPh. The Charlton Centre for Specialized Treatment. Hamilton, ON (Canada).

hugapharmacist@hotmail.com

Gabriel TORANI. BScPharm. Gabriel Torani et Habib Haddad,

Pharmaciens Inc. Montreal, QC (Canada). gtorani@spec-pharma.ca Brennan K. SMITH. PhD. CTC Communications Corp. Mississauga, ON (Canada).bsmith@ctccomm.com

Aaron SIHOTA. BScPharm, RPh. Faculty of Pharmaceutical

Sciences, University of British Columbia. Vancouver, BC (Canada). aaron.sihota@ubc.ca patient may decide to change RA pharmacotherapy during the course of disease progression. Most often this is due to no response at all or inadequate response or adverse reactions/intolerance to their current drug therapy. Patients not responding to therapy may be categorized as primary or secondary non-responders, the former due to initial complete lack of response, and the latter due to loss of responsiveness over time. ${ }^{2}$

EULAR (The European League Against Rheumatism) recently updated their recommendations for the treatment of RA in 2019. ${ }^{3}$ They recommend patients who fail a TNF-a inhibitor should switch to a different mechanism of action, rather than trying another TNF-a inhibitor within class.

Increasingly, some patients with RA are also being required to change therapy for non-clinical reasons. Typically, due to payor formulary constraints (often based on cost), some Canadian provinces are mandating a non-clinical transition from biologic originator to biosimilar. ${ }^{4,5}$ Biosimilars (or "subsequent-entry biologics") are akin to the biologic medicines' equivalent of chemical generics. ${ }^{6}$ The costsavings associated with biosimilars may ultimately improve patient access to biologics and other valuable medicines. ${ }^{7-9}$ There is a growing body of evidence that suggests switching to a biosimilar is safe and effective, however the very faint theoretical potential of developing immunogenicity along with the impact of the nocebo effect can create confusion 
for patients. ${ }^{10-14}$ Healthcare professionals must exercise their own clinical judgement when considering the suitability of transitions on a patient-by-patient basis. ${ }^{15}$ Considering the scenarios above, the pharmacist can expect to see more patients with RA undergoing complex therapeutic changes. Pharmacists are well positioned to guide and assist patients with appropriate clinical education as well as complete administrative tasks that can facilitate a smooth transition. Pharmacists typically follow patients more frequently and have more touchpoints than their rheumatologist does post-transition, so are ideally placed to flag any early safety or efficacy issues. This is especially the case with refilling medications which represent an opportunity to engage and monitor a patient.

There is currently limited practical guidance available for pharmacists who are managing transitions from originator biologic to another originator biologic, biosimilar, or JAKi. As biosimilars and novel mechanisms of action continue to enter the marketplace, there is an unmet need for pharmacist guidance on the key roles they can play during the therapeutic transition. A review of the literature yields a paucity of guidance, and other authors have highlighted this need when drawing their conclusions. ${ }^{16-18}$

In this paper we aim to create a monitoring algorithm for pharmacists to facilitate best practices throughout therapeutic transitions to biologics and JAKis in RA. It should be noted that although we have developed our guidance in the context of pharmacy practice in Canada, we believe it should still provide value regardless of clinical setting or jurisdiction. We encourage the reader to exercise best judgement when applying our guidance to their local regulatory policies.

\section{METHODS}

\section{General methodology}

A group of experts was gathered to address an unmet need for pharmacists to better understand the impact of patients being transitioned to new RA therapies, and how they can best support those patients and the rheumatologists. The Nominal Group Technique was used to establish a consensus among the group. A facilitator and assistant were appointed to moderate all group discussions and voting rounds.

\section{Participant selection}

The multidisciplinary participant committee was selected to represent both pharmacists and rheumatologists in multiple practice settings and geographies across Canada with clinical experience in assisting patients with inflammatory arthritis and related sequalae. Upon agreement to participate, the participants met virtually to discuss scope and a suitable methodology to find consensus.

\section{Nominal group technique}

The Nominal group technique (NGT) was used to understand if consensus could be found among the participants. NGT is a structured variation of a small group discussion that lends itself to finding a consensus especially when there is a goal of prioritizing free-structured ideas. ${ }^{19-21}$ The NGT was performed according to the methodology of McMillan et al. ${ }^{21}$

Some of the advantages of the NGT that made it particularly suitable for this application include: effective for smaller groups; balances the influence of individuals; allows for a greater number of ideas to be considered; allows the group to prioritize ideas democratically. ${ }^{22}$

The first step was alignment on the clinical need of the community pharmacist. This was achieved during a series of structured, moderated participant discussions in the virtual setting utilizing Zoom software (San Jose, USA). The methodological framework used was grounded theory. ${ }^{23} \mathrm{~A}$ list of clinically relevant questions was generated; some of which were discarded as out of scope, and some kept. The complete list, including outcome and rationale are included in Table 1. The refined list progressed to the voting round of the NGT.

The clinical questions that were identified fell into three categories:

1. Considerations prior to transition to another originator biologic therapy, biosimilar or JAK

2. Considerations during transition to another originator biologic therapy, biosimilar or JAK

3. Considerations after transition to another originator biologic therapy, biosimilar or JAK

\begin{tabular}{|l|l|l|}
\hline \multicolumn{1}{|c|}{ Table 1. Development of clinical questions } \\
\hline \multicolumn{1}{|c|}{ Proposed clinical question } & \multicolumn{1}{|c|}{ Outcome } & \multicolumn{1}{|c|}{ Rationale } \\
\hline $\begin{array}{l}\text { Pre-transition: How can pharmacists reduce the risk of a } \\
\text { nocebo effect? }\end{array}$ & Included & Participants agreed this topic is of major importance \\
\hline $\begin{array}{l}\text { Pre-transition: How to measure effectiveness of current } \\
\text { therapy as a baseline vs new therapy }\end{array}$ & Discarded & $\begin{array}{l}\text { Participants felt it was inappropriate to attempt this as it may } \\
\text { create the impression that we expect a change in effectiveness } \\
\text { post-transition. This could lead to a nocebo effect }\end{array}$ \\
\hline $\begin{array}{l}\text { Pre-transition: How does Covid-19 status impact choice or } \\
\text { timing of transition? }\end{array}$ & Discarded & $\begin{array}{l}\text { Although this is an interesting and timely topic, it was deemed } \\
\text { out of scope and potentially irrelevant at time of publication. }\end{array}$ \\
\hline $\begin{array}{l}\text { Pre-transition: In what circumstances should the pharmacist } \\
\text { refer back to the rheumatologist prior to transition? }\end{array}$ & Included & Participants agreed this topic is of major importance \\
\hline $\begin{array}{l}\text { During transition: What are the clinical considerations that a } \\
\text { pharmacist should be aware of during a therapeutic switch? }\end{array}$ & Included & Participants agreed this topic is of major importance \\
\hline $\begin{array}{l}\text { During transition: What are the administrative considerations } \\
\text { when starting a new treatment? }\end{array}$ & Included & Participants agreed this topic is of major importance \\
\hline $\begin{array}{l}\text { After transition: What tools should pharmacists use to assess } \\
\text { disease activity? }\end{array}$ & Included & Participants agreed this topic is of major importance \\
\hline $\begin{array}{l}\text { After transition: When should a pharmacist refer for earlier } \\
\text { than scheduled follow up with the rheumatologist? }\end{array}$ & Included & Participants agreed this topic is of major importance \\
\hline After transition: When to refer to rheumatologist for safety? & Included & Participants agreed this topic is of major importance \\
\hline
\end{tabular}




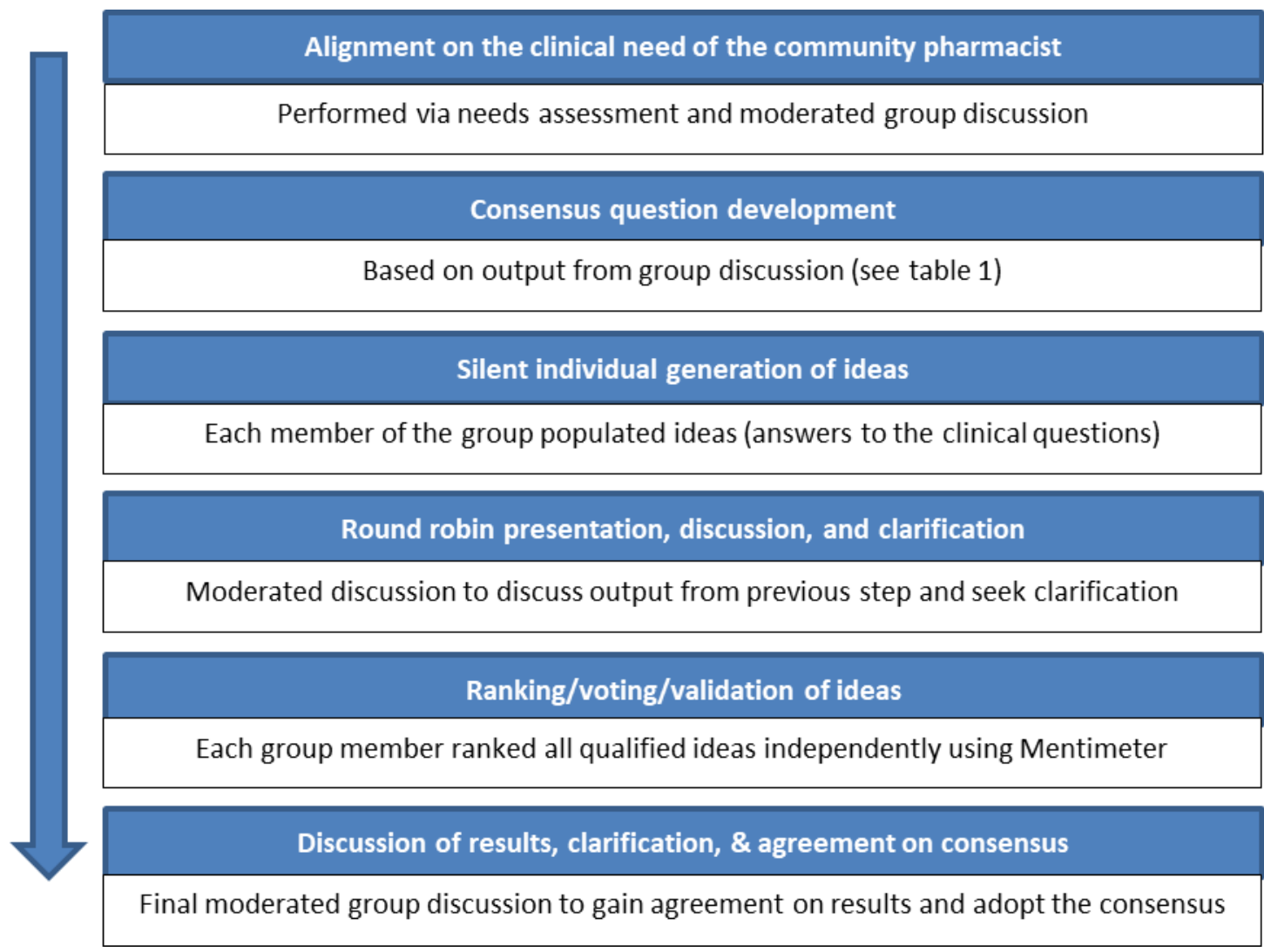

Figure 1. Nominal group technique process

Once the clinical questions were established, the formal NGT could begin (Figure 1). Step two was a silent generation of ideas where the participants considered the questions as individuals, and privately generated answers/ideas.

Step three was a round robin, where each question was discussed as a group, along with a comprehensive list of ideas that had been generated in the previous step. After discussion and consideration, the participants ranked the ideas using the online polling tool, Mentimeter (Stockholm, Sweden). ${ }^{24}$

Once all questions had been addressed, the group in realtime discussed the results and established a consensus. When ranking the questions, the group agreed that the top three ideas would be selected as their consensus. In cases where ranking was deemed inappropriate, or if the group felt all ideas were equally important, they abstained from voting and agreed that a comprehensive list was the best outcome.

\section{RESULTS}

The results of the iterations of voting and discussion were developed into a clinical decision-making monitoring tool (Figure 2). The below commentary highlights where the participants believe they could find (or not find) a consensus and establish a recommendation for pharmacists. A full list of questions and responses, including voting results can be found in Table 2 and Table 3 .

\section{Considerations prior to transition to another therapy}

Question 1: How can pharmacists reduce the risk of a nocebo effect? The nocebo effect is defined as a negative effect of a pharmacological or non-pharmacological medical treatment that is induced by patients' expectations, and that is unrelated to the physiological action of the treatment. ${ }^{25}$ The most important factor in reducing the risk of a nocebo effect is for the pharmacist to demonstrate confidence in the transition using positive verbal language. The next most important factor is using positive body language. And the third most important factor is consistent messaging from all healthcare providers. The participants did not see the value of using a validated tool to screen and assess patient attitudes towards the therapeutic transition as a proxy for potential nocebo.

Question 2: In what circumstances should the pharmacist refer back to the rheumatologist prior to transition? Before transition, a pharmacist must receive a new prescription. However, if the pharmacist believes there is a significant safety, efficacy, or other concern that may lead to a poor outcome, they should discuss with the prescribing rheumatologist prior to the transition. The participants felt it would be impractical to reach a consensus on this question as there are many factors that are specific to an individual patient or circumstance. Depending on severity or seriousness, any factor could be deemed important enough to warrant a referral or at least a query to the rheumatologist. The pharmacist should exercise their own professional judgement. 


\section{Monitoring the transition of patients on biologics in rheumatoid arthritis: Consensus guidance for pharmacists}

\begin{tabular}{|c|c|c|}
\hline 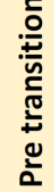 & $\begin{array}{l}\text { Avoid the nocebo effect for biosimilars } \\
\text { - Use positive verbal language } \\
\text { - Use positive body language } \\
\text { - Ensure messaging is aligned with other } \\
\text { HCPS }\end{array}$ & $\begin{array}{l}\text { When to flag a transition to a biosimilar } \\
\text { - Suspect history of immunogenicity } \\
\text { - Indication not approved } \\
\text { - New co-morbidity OR formulation specific } \\
\text { contraindication }\end{array}$ \\
\hline
\end{tabular}

\begin{tabular}{|c|c|c|}
\hline $\begin{array}{l}\text { TNF } \alpha \text { inhibitors }{ }^{\text {a }} \\
\text { - Injection site reactions } \\
\text { - URTI } \\
\text { - MS or CHF symptoms* }\end{array}$ & $\begin{array}{l}\text { Rituximab } \\
\text { - Infusion reactions } \\
\text { - } \text { PML* }^{*} \\
\text { - Tumor lysis syndrome* }\end{array}$ & $\begin{array}{l}\text { Anakinra } \\
\text { - Injection site reactions } \\
\text { - Immunogenicity }\end{array}$ \\
\hline $\begin{array}{l}\text { Sarilumab, tocilizumab } \\
\text { - Headache + injection-site } \\
\text { reaction } \\
\text { - Lipids and liver function } \\
\text { - Neutrophil \& platelet counts } \\
\text { - } \text { Diverticulitis* }\end{array}$ & $\begin{array}{l}\text { Abatacept } \\
\text { - } \quad \text { URTI, N,D, headache } \\
\text { - May worsen Chronic } \\
\text { Obstructive Pulmonary } \\
\text { Disease (COPD)* } \\
\text { - Injection site reactions* }\end{array}$ & $\begin{array}{l}\text { JAK inhibitors } \\
\text { - URTI, nausea, diarrhea } \\
\text { - Lipids and liver function } \\
\text { - Renal dose adjustment (only } \\
\text { true for baricitinib and } \\
\text { tofacitinib) }\end{array}$ \\
\hline
\end{tabular}

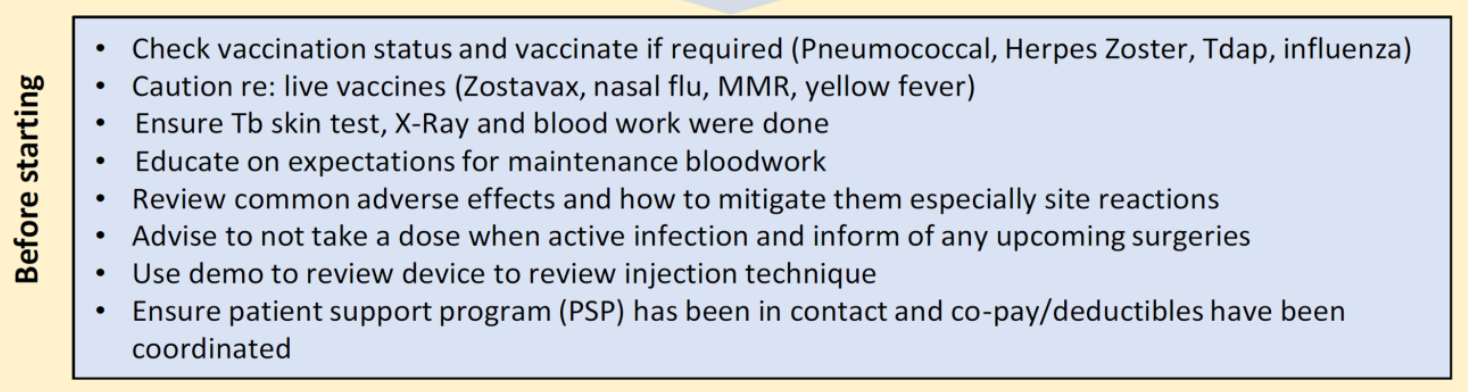

\begin{tabular}{|c|}
\hline $\begin{array}{l}\text { Use one of the following tools, and keep a record of responses to monitor efficacy of treatment over } \\
\text { time. Repeat at each refill, or every } \mathbf{3} \text { months, whichever is sooner. } \\
\text { Visual Analog Scale: Best for quick assessment, cannot be done on the phone } \\
\text { RAPID3: Longer tool but most sensitive for RA } \\
\text { Likert Scale: Can be customized and quick to complete on phone or in pharmacy }\end{array}$ \\
\hline
\end{tabular}

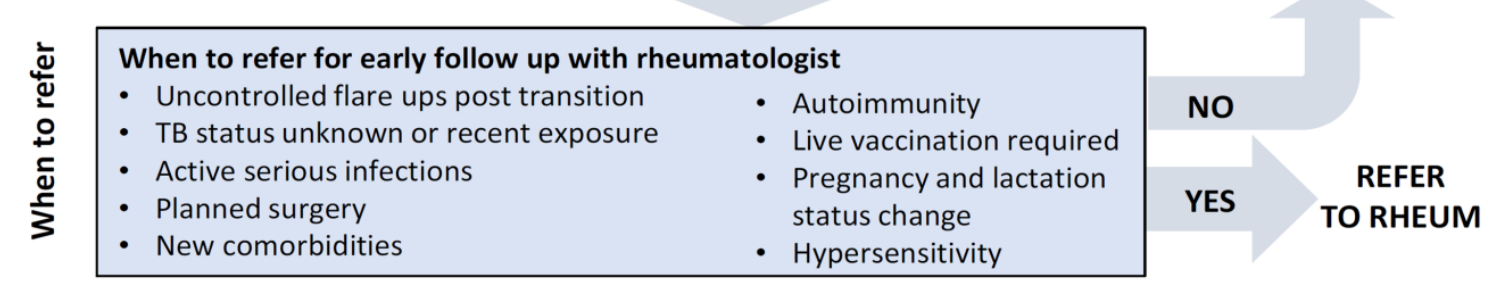

aTNF $\alpha$ inhibitors: infliximab, etanercept, adalimumab, golimumab, certolizumab

bJAK inhibitors: tofacitinib, baricitinib, upadacitinib

*Indicates less common side effect incidence

URTI: Upper respiratory tract infection (eg. Sinusitis)

Figure 2. Clinical decision-making monitoring tool to facilitate best practices throughout therapeutic transitions to biologics and Janus kinase inhibitors in rheumatoid arthritis

\section{Considerations during transition}

Question 3: What are the clinical considerations that a pharmacist should be aware of during a therapeutic switch? The participants agreed that this question should be split to be specific and relevant to the mechanism of action and the mode of administration of the new therapy.
A list of clinical considerations based on the mechanism of action for each therapeutic category was therefore developed (Figure 2).

Question 4: What are the administrative considerations when starting a new treatment? The participants agreed that ranking the responses to this question was not 


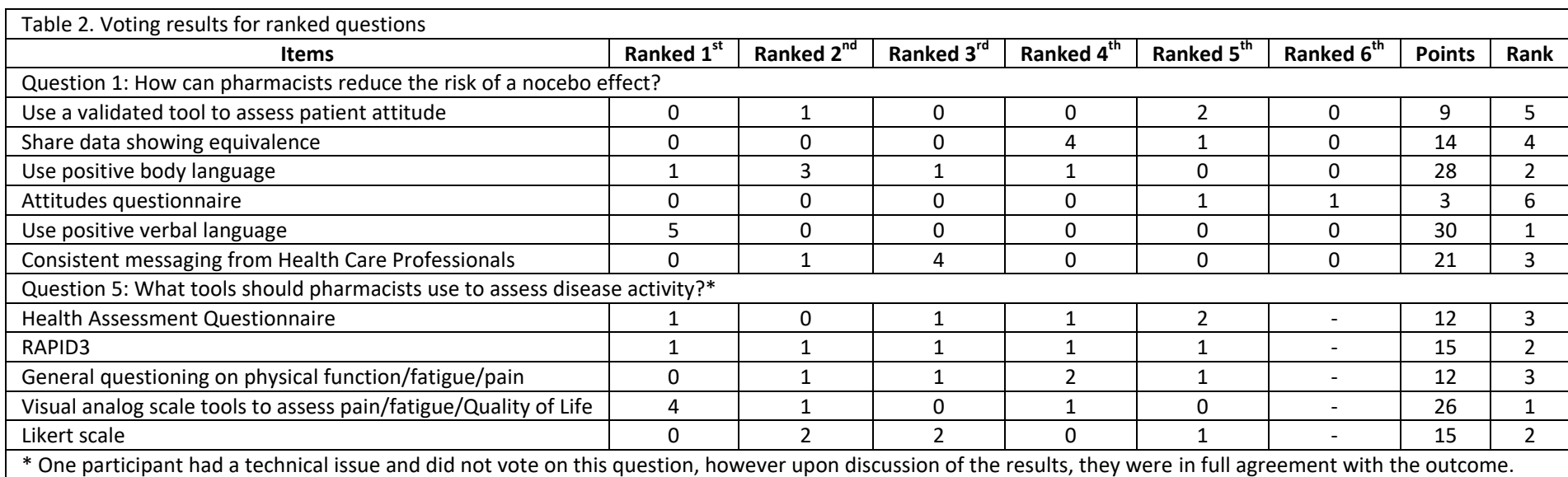

appropriate. All responses were deemed important and the group agreed that providing a complete list of considerations would be more valuable than prioritizing.

\section{Considerations after transition}

Question 5: What tools should pharmacists use to assess disease activity? The participants voted on this question and the most important tool was found to be a Visual Analog Scale (VAS) to assess pain/fatigue/quality of life. The next two most important tools to consider are the RAPID3 tool and the Likert Scale. The Health Assessment Questionnaire (HAQ) and a general questioning approach were deemed less important.

Question 6: When should a pharmacist refer for earlier than scheduled follow up with the rheumatologist? Question 6 was not ranked as the participants agreed that similar to question 2, the seriousness and severity of the individual factors (infection, repeated flare ups, surgery, live vaccinations etc.) are more important than the factors themselves. They noted however that, as a rule, unmanaged flares that are significantly impacting on health-related quality of life (HRQoL) or functioning should be referred for early follow up. They also noted that the pharmacist is well positioned to monitor and resolve issues relating to adherence and safety.

Question 7: When to refer to rheumatologist for safety? There was a lengthy list of situations where a referral for safety concerns was warranted. The participants agreed that all were legitimate and for that reason it was not appropriate to rank importance. The entire list should be included in no specific order.

Based on the outcome of the consensus discussions, an algorithm was created to help guide pharmacists through therapeutic transitions in RA (Figure 2).

\section{DISCUSSION}

Based on our results, we have created a tool to guide pharmacists through the transition process, highlighting areas where they can have the most positive impact.

Pre-transition considerations include being aware of possible nocebo effects for biosimilars. Although a biosimilar and its reference product have an identical amino acid sequence, subtle differences in post- translational modifications that occur during the manufacturing process in living organisms can be expected. ${ }^{26}$ For this reason, there are occasional reservations among the medical and patient communities regarding the transition from originator products to biosimilars when a patient is otherwise stable, in lowdisease activity or in Boolean remission. ${ }^{27}$ These reservations can manifest a nocebo response in the patient. ${ }^{14,25,28}$ However, a 2018 consensus document by the Task Force on the Use of Biosimilars to Treat Rheumatological Diseases states that the currently available scientific evidence indicates that a single switch from a reference to a biosimilar is safe and effective. ${ }^{29}$ Additionally, clinical trials assessing switch from a biooriginator to a biosimilar have not demonstrated any loss of efficacy, increase in adverse events, or increased immunogenicity. ${ }^{11,12}$ A recent systemic review of switching between originator biologics and biosimilars confirms this further. ${ }^{30}$ Finally, it should also be noted that posttranslational modifications can also occur between batches of the same originator biologic, so this phenomenon is not a unique characteristic of biosimilars. The participants noted the importance of avoiding the nocebo effect by using positive verbal and body language and aligning with consistent messaging from all health care professionals to the patient. Patients should receive simple and understandable language, as well as a tailored approach when talking to clinicians. Some patients will require more information, other will not. It is the task of all clinicians (nurse, physicians, pharmacist) to assess the individual patient needs. On the one hand, one wants to avoid giving too much information and creating doubts. On the other hand, clinicians should also avoid giving too little information. ${ }^{30,31}$

Other clinical considerations prior to the transition are mechanism of action specific. The most pertinent clinical concerns that the pharmacist should be aware of are listed for each of the mechanism of action classes. ${ }^{32-36} \mathrm{~A}$ "before starting" checklist for the pharmacist is included - a convenient reminder of the most important administrative tasks that should be completed to ensure a smooth transition to the new therapy. The pharmacist is well positioned to assist with transition to the new patient support program (PSP), an area noted for commonly causing distress for patients and uncertainty for rheumatologists. 


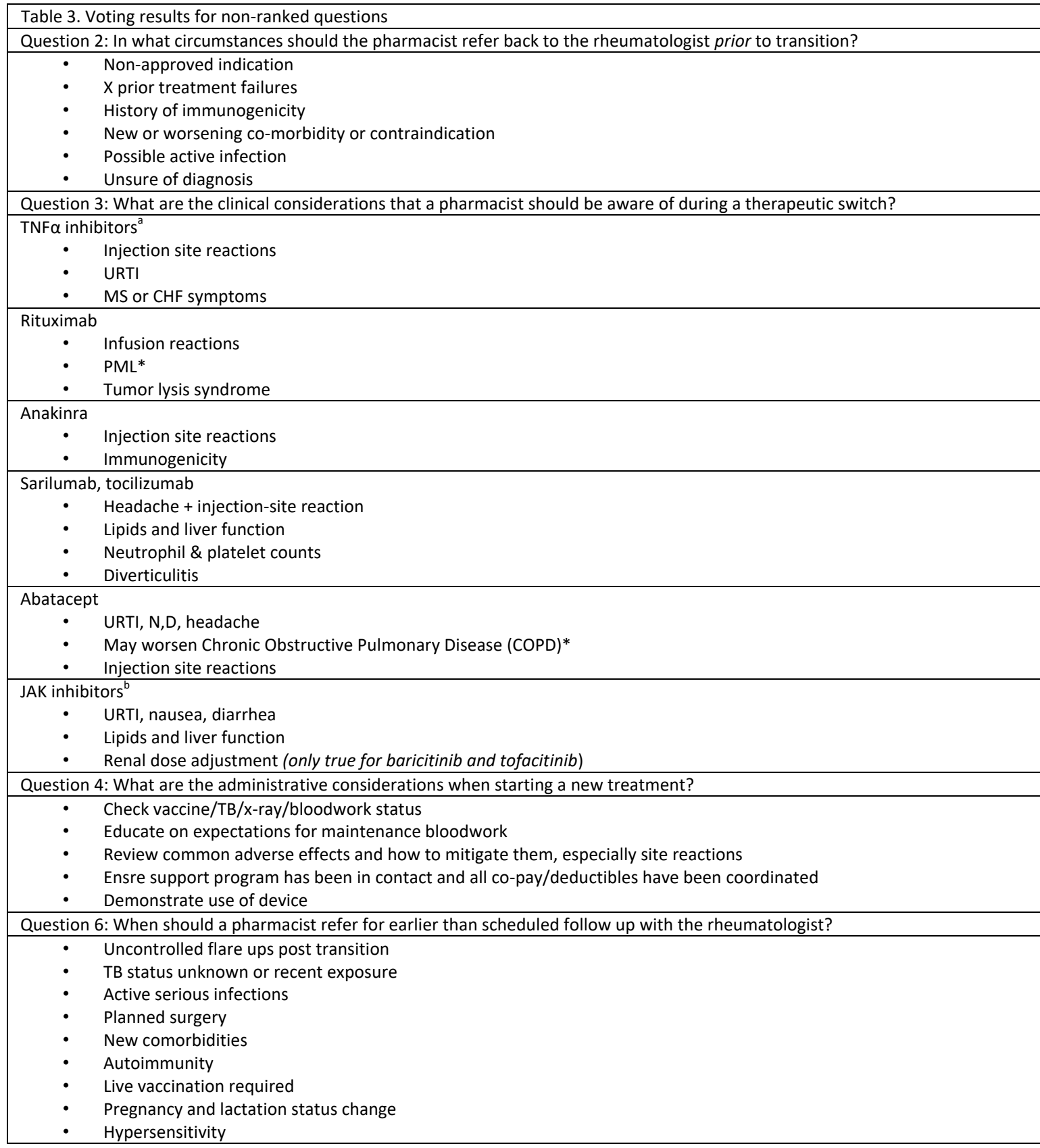

A consensus was reached regarding monitoring the patient for signs of primary non-response. The pharmacist is likely going to interact with the patient for medication refills before the scheduled three to six-month follow-up appointment with the rheumatologist. Although a lack of peak-response early in treatment is not particularly concerning, a series of uncontrolled or frequent flare ups as compared to baseline after 3 months of therapy would be cause for immediate referral. There was strong agreement among the participants that the pharmacist should monitor for changes in symptoms such as pain, fatigue, and quality of life using a simple visual tool such as the visual analog scale (VAS). The RAPID3 questionnaire and Likert Scale tools ranked second and third respectively. VAS and Likert responses are highly correlated and yield similar precision. Since Likert responses are easier to administer and interpret, some pharmacists may find it preferable. ${ }^{37}$
RAPID3 is a validated tool for RA so some may prefer its specificity and greater accuracy. ${ }^{38}$

The final section of the clinical monitoring tool developed lists scenarios for early referral to the rheumatologist. Although the list could never be exhaustive, there was unanimous agreement that the most common issues have been captured. As previously mentioned, uncontrolled and frequent flares as compared to patient baseline are a cause for concern and should be referred. But it should be noted that flares are a common and expected feature of RA, even in well controlled patients. Depending on the setting, pharmacists may be able to help their patients manage flares, using non-steroidal anti-inflammatory drugs (NSAIDS), a short course of steroids, or titration of other anti-rheumatic agents. 


\section{Implication to pharmacy practice}

Our aim was to create a concise quick reference tool that would be practically useful to a pharmacist in any setting. It serves as both a reference and a checklist and can be applied to any situation where a patient is transitioning from one RA therapy to another. The tool is easy to use with logical progression from pre-transition considerations to post-transition monitoring. It answers the identified unmet need for pharmacists, specifically how to talk to patients about biosimilars, when to flag a potentially inappropriate transition, and how to monitor for efficacy.

The tool could be used in hospital, community, or specialty settings. As it is all contained on one page, we would suggest it can be printed and posted in a dispensary or made available on a dispensary computer for quick reference when preparing to counsel a patient. Depending on local policies and practice, it could also be converted and used as a checklist.

\section{CONCLUSIONS}

New classes of anti-rheumatic drugs including JAKs, along with the introduction of biosimilars are presenting more opportunity for therapeutic changes in patients with RA. These changes are often complex due to the nature of the drugs, along with an associated administrative burden. Pharmacists are well positioned to manage the transition and be an advocate for the patient. We hope our novel clinical guidance and monitoring tool will assist pharmacists in supporting their patients to a successful therapeutic transition and allow for a greater role in their overall care.

\section{ACKNOWLEDGEMENTS}

The authors would like to acknowledge the assistance of Andrew O'Reilly of Pinewood Digital Consulting in developing the manuscript.

\section{CONFLICT OF INTEREST}

$\mathrm{JC}$ is a consultant for Abbvie, Amgen, Celgene, Eli Lilly, Gilead, Janssen, Novartis, Pfizer, Roche, and UCB, and has received grant/research support from Abbvie, UCB, Novartis, and Pfizer.

DC is a consultant and occasional speaker for Abbvie, Amgen, Celgene, Eli Lilly, Gilead, Milan, Novartis, Pfizer, Roche, Sandoz, Tevapharm and UCB.

AS is has been a consultant and occasional speaker for Abbvie, Amgen, Aspen, Eli Lilly, Emergent, JNJ, Merck, Pfizer and Spectrum Therapeutics.

GT has been a conferencier for Abbvie, AstraZeneca, Pfizer, Sandoz, and Sanofi.

CW has been a consultant/advisor for UCB and Janssen and has received grants/honoraria from Amgen, AbbVie, Janssen, Merck, Pfizer, and UCB.

\section{FUNDING}

This research was supported by an IME (independent medical education) grant from Abbvie Canada Inc. Abbvie did not influence the design, development or conduct of the study. Abbvie did not influence the collection, management, analysis, or interpretation of the data, nor influence the preparation, review, approval of the manuscript, or decision to submit the manuscript for publication.

\section{AUTHOR ROLES (CRediT)}

Conceptualization: AS.

Data curation: AS, BKS.

Formal analysis: AS, BKS.

Funding acquisition: AS.

Investigation: AS, BKS, JC, CW, GT, DC, MB.

Methodology: AS, BKS.

Project administration: AS, BS.

Resources: AS, BKS.

Software: BS.

Supervision: AS.

Validation: AS, BKS.

Visualization: AS, BKS, JC, CW, GT, DC, MB.

Writing - original draft: BKS.

Writing - review \& editing: AS, BKS, JC, CW, GT, DC, MB.

\section{References}

1. Kuek A, Hazleman BL, Ostör AJ. Immune-mediated inflammatory diseases (IMIDs) and biologic therapy: a medical revolution. Postgrad Med J. 2007;83(978):251-260. https://doi.org/10.1136/pgmj.2006.052688

2. Rubbert-Roth $A$, Finckh $A$. Treatment options in patients with rheumatoid arthritis failing initial TNF inhibitor therapy: a critical review. Arthritis Res Ther. 2009;11 Suppl 1(Suppl 1):S1. https://doi.org/10.1186/ar2666

3. Smolen JS, Landewé RBM, Bijlsma JWJ, et al. EULAR recommendations for the management of rheumatoid arthritis with synthetic and biological disease-modifying antirheumatic drugs: 2019 update. Ann Rheum Dis. 2020;79(6):685-699. https://doi.org/10.1136/annrheumdis-2019-216655

4. Government of Alberta. Biosimilar drugs. https://www.alberta.ca/biosimilar-drugs.aspx (accessed Oct 28, 2020).

5. British Columbia Government. Biosimilars FAQ for prescribers. https://www2.gov.bc.ca/gov/content/health/practitionerprofessional-resources/pharmacare/prescribers/biosimilars-initiative-prescribers/biosimilars-faq-prescribers\#PSP (accessed Jul 7, 2020)

6. Weise M, Bielsky MC, De Smet K, et al. Biosimilars: what clinicians should know. Blood. 2012;120(26):5111-5117. https://doi.org/10.1182/blood-2012-04-425744

7. Kim JW, Jung JY, Suh $\mathrm{CH}$. Real-world observational study of biosimilars in inflammatory arthritis treatment: a systematic literature review. Expert Opin Biol Ther. 2021;21(1):57-73. https://doi.org/10.1080/14712598.2020.1812575 
8. Mansell $\mathrm{K}$, Bhimji $\mathrm{H}$, Eurich $\mathrm{D}$, Mansell $\mathrm{H}$. Potential cost-savings from the use of the biosimilars filgrastim, infliximab and insulin glargine in Canada: a retrospective analysis. BMC Health Serv Res. 2019;19(1):827. https://doi.org/10.1186/s12913-019-4680-2

9. Mezones-Holguin E, Gamboa-Cardenas RV, Sanchez-Felix G, et al. Efficacy and Safety in the Continued Treatment With a Biosimilar Drug in Patients Receiving Infliximab: A Systematic Review in the Context of Decision-Making From a LatinAmerican Country. Front Pharmacol. 2019;10:1010. https://doi.org/10.3389/fphar.2019.01010

10. Cohen HP, Blauvelt A, Rifkin RM, Danese S, Gokhale SB, Woollett G. Switching Reference Medicines to Biosimilars: A Systematic Literature Review of Clinical Outcomes. Drugs. 2018;78(4):463-478. https://doi.org/10.1007/s40265-018-0881y

11. Jørgensen KK, Olsen IC, Goll GL, et al. Switching from originator infliximab to biosimilar CT-P13 compared with maintained treatment with originator infliximab (NOR-SWITCH): a 52-week, randomised, double-blind, non-inferiority trial. Lancet. 2017;389(10086):2304-2316. https://doi.org/10.1016/s0140-6736(17)30068-5

12. Gerdes S, Thaçi D, Griffiths CEM, et al. Multiple switches between GP2015, an etanercept biosimilar, with originator product do not impact efficacy, safety and immunogenicity in patients with chronic plaque-type psoriasis: 30-week results from the phase 3, confirmatory EGALITY study. J Eur Acad Dermatol Venereol. 2018;32(3):420-427. https://doi.org/10.1111/idv.14605

13. Toussirot E, Marotte H. Switching from originator biological agents to biosimilars: what is the evidence and what are the issues?. RMD Open. 2017;3(2):e000492. https://doi.org/10.1136/rmdopen-2017-000492

14. Kristensen LE, Alten R, Puig L, et al. Non-pharmacological Effects in Switching Medication: The Nocebo Effect in Switching from Originator to Biosimilar Agent. BioDrugs. 2018;32(5):397-404. https://doi.org/10.1007/s40259-018-0306-1

15. FDA. Biosimilar and interchangeable biologics: more treatment choices. https://www.fda.gov/consumers/consumerupdates/biosimilar-and-interchangeable-biologics-more-treatment-choices (accessed Jul 8, 2020).

16. Foreman E, Patel H, Siderov J, Harchowal J, Bubalo J, Chan A. A survey of global biosimilar implementation practice conducted by the International Society of Oncology Pharmacy Practitioners. J Oncol Pharm Pract. 2020;26(3_suppl):22 32. https://doi.org/10.1177/1078155220913098

17. Scott BJ, Klein AV, Wang J. Biosimilar monoclonal antibodies: A Canadian regulatory perspective on the assessment of clinically relevant differences and indication extrapolation. J Clin Pharmacol. 2015;55(Suppl 3):S123-S132. https://doi.org/10.1002/jcph.339

18. Endrenyi L, Jamali F, Loebenberg R. Subsequent Entry Biologics in Canada: Current State of the Science. J Pharm Pharm Sci. 2015;18(2):177-183. https://doi.org/10.18433/38s3h

19. Nominal group technique (ngt): nominal brainstorming steps. https://asq.org/quality-resources/nominal-group-technique (accessed Oct 19, 2020).

20. Harvey N, Holmes CA. Nominal group technique: an effective method for obtaining group consensus. Int J Nurs Pract. 2012;18(2):188-194. https://doi.org/10.1111/i.1440-172x.2012.02017.x

21. McMillan SS, King M, Tully MP. How to use the nominal group and Delphi techniques. Int J Clin Pharm. 2016;38(3):655 662. https://doi.org/10.1007/s11096-016-0257-x

22. CDC. Gaining consensus among stakeholders through the nominal group technique. https://www.cdc.gov/healthyyouth/evaluation/pdf/brief7.pdf (accessed Jun 3, 2021).

23. Charmaz K, Belgrave LL. Grounded theory. In: Ritzer G, ed. The Blackwell encyclopedia of sociology. Hoboken, NJ: Wiley; 2015. ISBN: 9781405124331

24. Interactive presentation software: Mentimeter. https://www.mentimeter.com/ (accessed Oct 28, 2020).

25. Pouillon L, Socha M, Demore B, et al. The nocebo effect: a clinical challenge in the era of biosimilars. Expert Rev Clin Immunol. 2018;14(9):739-749. https://doi.org/10.1080/1744666x.2018.1512406

26. Edwards CJ, Hercogová J, Albrand H, Amiot A. Switching to biosimilars: current perspectives in immune-mediated inflammatory diseases. Expert Opin Biol Ther. 2019;19(10):1001-1014. https://doi.org/10.1080/14712598.2019.1610381

27. The Arthritis Society. The Arthritis Society position on biosimilars. https://www.arthritis.ca/AS/media/pdf/Treatment/Biosimilars-Position-Paper-January-2018-FINAL-EN.PDF (accessed Oct 28, 2020)

28. Rezk MF, Pieper B. Treatment Outcomes with Biosimilars: Be Aware of the Nocebo Effect. Rheumatol Ther. 2017;4(2):209-218. https://doi.org/10.1007/s40744-017-0085-z

29. Kay J, Schoels MM, Dörner T, et al. Consensus-based recommendations for the use of biosimilars to treat rheumatological diseases. Ann Rheum Dis. 2018;77(2):165-174. https://doi.org/10.1136/annrheumdis-2017-211937

30. Barbier L, Ebbers HC, Declerck P, Simoens S, Vulto AG, Huys I. The Efficacy, Safety, and Immunogenicity of Switching Between Reference Biopharmaceuticals and Biosimilars: A Systematic Review. Clin Pharmacol Ther. 2020;108(4):734755. https://doi.org/10.1002/cpt.1836

31. Vandenplas Y, Simoens S, Van Wilder P, Vulto AG, Huys I. Informing Patients about Biosimilar Medicines: The Role of European Patient Associations. Pharmaceuticals (Basel). 2021;14(2):117. https://doi.org/10.3390/ph14020117

32. Abbvie Corporation. Humira Product Monograph. https://www.abbvie.ca/content/dam/abbviecorp/ca/en/docs/HUMIRA PM EN.pdf (accessed Oct 28, 2020).

33. ULC PC. Xeljanz Product Monograph. https://www.pfizer.ca/sites/default/files/201910/XELJANZ PM E 230976 24Oct2019.pdf (accessed Oct 28, 2020).

34. Roche H-L. Rituxan Product Monograph. Toxicology. https://www.rochecanada.com/PMs/Rituxan/RituxanIV PM E.pdf (accessed Oct 28, 2020).

35. Canada B-MS. Orencia Product monograph. https://www.bms.com/assets/bms/ca/documents/productmonograph/ORENCIA EN PM.pdf (accessed Oct 28, 2020). 
Choquette D, Chan J, Bardi M, Whiskin C, Torani G, Smith BK, Sihota A. Monitoring the transition of patients on biologics in rheumatoid arthritis: Consensus quidance for pharmacists. Pharmacy Practice 2021 Jul-Sep;19(3):2377.

https://doi.org/10.18549/PharmPract.2021.3.2377

36. Swedish Orphan Biovitrum. Kinaret Product monograph. https://pdf.hres.ca/dpd pm/00044494.PDF (accessed Oct 28, 2020).

37. Bolognese JA, Schnitzer TJ, Ehrich EW. Response relationship of VAS and Likert scales in osteoarthritis efficacy measurement. Osteoarthr Cartil. 2003;11(7):499-507. https://doi.org/10.1016/S1063-4584(03)00082-7

38. Pincus T, Yazici Y, Bergman MJ. RAPID3, an index to assess and monitor patients with rheumatoid arthritis, without formal joint counts: similar results to DAS28 and CDAI in clinical trials and clinical care. Rheum Dis Clin North Am. 2009;35(4):773-778. https://doi.org/10.1016/j.rdc.2009.10.008 